Honigeld, G. \& PATIN, J. (1990) A two-year clinical and economic follow-up of patients on clozapine. Hospital and Community Psychiatry, 41, 882-885

Meltzer, H. Y., Burnett, S., BAstani, B., et al (1990) Efiects of six months of clozapine treatment on the quality of life of schizophrenic patients. Hospital and Community Psychiatry, 41. 892-897.

Institute of Psychiatry

De Crespigny Park

London SE5 8 AZ

Geraldine STRATHDEE

KAREN JONES

Maudsley Hospital

Denmark Hill

London SE5 8 AZ

\section{ECT anaesthetics}

SIR: I read with interest the audit of ECT in two NHS regions by Pippard (Journal, May 1992, 160, 621-638) which was a fascinating follow-up to his earlier work. As an anaesthetist with responsibility for provision of anaesthesia to an ECT treatment unit, I would like to comment on one small point. Dr Pippard states quite correctly that the use of propofol is probably contraindicated for ECT, because it reduces seizure duration. Therefore methohexitone remains the agent of choice, particularly in view of its proconvulsant potential. Unfortunately, the injection of methohexitone is often painful, and repeated anaesthesia with this agent can be distressing for some patients. Dr Pippard stated that the use of $10 \mathrm{mg}$ lignocaine with anaesthetic induction agents is not recommended because of the potential anticonvulsant activity of this local anaesthetic. The use of lignocaine to modify the pain of injection of methohexitone during anaesthesia for electroconvulsive therapy has been studied (Simpson et al, 1989). We showed that pain on injection of methohexitone occurred in nearly half of the patients, and in a quarter of them pain was reported as moderate or severe. The use of $10 \mathrm{mg}$ lignocaine before or mixed with the methohexitone reduced this significantly. We measured seizure duration using an isolated arm technique and demonstrated that the use of $10 \mathrm{mg}$ lignocaine did not significantly affect seizure duration. In view of these findings I would urge that lignocaine continue to be used routinely when injecting methohexitone into a vein on the dorsum of the hand, particularly when patients are to undergo repeated anaesthesia.

Simpson, K. H., Halsall, P. J., Sides, C. A., et al (1989) Pain on injection of methohexitone. The use of lignocaine to modify pain on injection of methohexitone during anaesthesia for electroconvulsive therapy. Anaesthesia, 44, 688-689.

\section{K. H. SimPSON}

Department of Anaesthesia

St James's University Hospital

Beckett Street

Leeds LS9 7TF

\section{Out-patient ECT for depression in a man with moderate learning disability}

There is little written on the place of ECT in the treatment of mental illness in those with learning disabilities (Lazarus et al, 1990). We would like to report the case of a 69-year-old man with moderate learning disability (IQ of 40).

Case report. Mr X presented with a six-week history of weepiness, lethargy, social withdrawal, weight loss, and poor sleep following an uneventful inguinal hernia repair. On examination he looked sad and described his mood as such. He spoke in monosyllables and complained of aches and pains in his feet (for which no organic cause was found). He had a past history of depression, following a previous inguinal hernia repair at age 61 years, which responded to tricyclic antidepressants. Otherwise he had always been in good health. A diagnosis of depression was made. Dothiepin, $50 \mathrm{mg}$ daily, was started, increasing to $150 \mathrm{mg}$ daily. However, he became more agitated and distressed. He was preoccupied with being unable to swallow, believed he had no throat and ate very little. He lost over $13 \mathrm{~kg}$ (two stones) in weight. His self-care skills deteriorated and he became doubly incontinent. The dothiepin was discontinued after two months and replaced with fluoxetine, $20 \mathrm{mg}$ daily, increasing to $40 \mathrm{mg}$ daily with no improvement after one month. At this stage his permission to commence ECT was sought and given. He received 11 bilateral treatments. After the first treatment a marked improvement in his appetite was noted with a reduction in his agitation. This continued to improve, as did his sleep; his bodily preoccupations and delusions then faded, followed lastly by a reduction of his social withdrawal. Three months later he is considered to be his 'old self' and is on fluoxetine, $40 \mathrm{mg}$ daily.

This case adds to the small literature on the use of ECT in those with learning disability and mental illness. The majority of the cases described are, as is this one, of major depression. Goldstein \& Jensvold's (1989) case bears particular similarities in that their patient's depression was seemingly precipitated by a surgical procedure. Kearns (1987) described a case of a man with learning disabilities with Cotard's syndrome who responded to ECT. In the present case the patient similarly denied the existence of part of his body (his throat). Our patient had ECT as an outpatient. Lazarus et al (1990) advocate the use of this, 